\title{
FAMILIAL OCCURRENCE OF CHRONIC RESPIRATORY DISEASE AND FAMILIAL RESEMBLANCE IN VENTILATORY CAPACITY
}

\author{
Millicent Higgins and $\mathrm{J}_{\mathrm{ACOB}}$ Keller \\ School of Public Health, University of Michigan, Ann Arbor, Michigan 48108
}

(Received in revised form 1 October 1974)

\section{INTRODUCTION}

MEMBERs of families share genes and adopt similar ways of life. They may, therefore, be expected to resemble one another in experience of disease and in physiological function. There is also diversity within families both in inheritance and in environmental exposures. Patterns of disease and distributions of physiological variables in the population and in families should, therefore, provide clues concerning determinants of disease and physiological function. The purpose of this paper is to see whether three common chronic respiratory conditions aggregate in families and whether members of families resemble one another in ventilatory lung function.

\section{METHODS}

Between 1962 and 1965, 9226 residents of Tecumseh were examined. These persons constituted 82 per cent of the population of a natural community which has been involved in a comprehensive, prospective epidemiological investigation of health and disease since 1959. The principal aim of the study is to identify causes and precursors of coronary heart disease, chronic respiratory disease, hypertension, diabetes mellitus and arthritis. Details of the aims and methods of the Tecumseh Community Health Study have been published [1-3]. Trained lay interviewers completed questionnaires in the subject's homes. Kindred or blood relationships were ascertained together with some demographic, social and medical information. Standard questions were asked about cardiovascular, respiratory and other symptoms and conditions, and smoking habits were recorded. Participants then attended a special clinic where physicians from the University of Michigan reviewed and amplified the histories, did physical examinations and diagnosed conditions present either currently or in the past. Additional clinic procedures included physical and anthropometric measurements, $X$-rays of the chest and hands, resting and exercise electrocardiograms, tests of ventilatory lung function and blood and urine analyses. Thirteen genetic markers have been determined. Subsequent processing of the data included diagnosis of chronic bronchitis, asthma and allergic rhinitis in accordance with the following criteria for probable disease [4]. 


\section{Chronic bronchitis}

The diagnosis was made when cough and phlegm were said to be present for at least three months out of the year. Standard questions were asked only of adults aged 16 and over. Chronic bronchitis was not diagnosed in children aged 15 or less.

\section{Asthma}

The diagnosis was made when asthma or wheeze was reported and associated with two of the following conditions:

(1) (a) attacks of shortness of breath or (b) trouble breathing out.

(2) exposure to allergens.

(3) asthma or asthmatic or wheezy bronchitis was diagnosed by the examining physician.

Standard questions were asked of all subjects; mothers generally responded for children aged 15 or less.

\section{Allergic rhinitis}

The diagnosis was made when hay fever or sinus trouble or persistent stuffy or runny nose was reported and associated with two of the following conditions:

(1) Itching of eyes, nose or throat or burning, watering, or redness of eyes.

(2) Exposure to allergens.

(3) Hay fever or allergic rhinitis was diagnosed by the examining physician.

If sinus trouble or nasal symptoms were reported, one of the two conditions had to be number (3).

Standard questions were asked of all subjects; mothers generally responded for children aged 15 or less.

Only conditions which were present at the time of cxamination or in the preceding year have been included in these analyses.

Lung function was measured with a Wedge* spirometer and volume and flow outputs were recorded on a Sanborn two-channel recorder at a paper speed of 25 $\mathrm{mm} / \mathrm{sec}$. Two satisfactory tracings were obtained for each subject and seven indices of ventilatory capacity were measured or derived from the tracing with the larger vital capacity [5]. The forced expiratory volume at 1 second (F.E.V.) $)_{1.0}$ is the only measure considered in this report.

Since ventilatory function is strongly related to age, sex and height, age- and heightadjusted scores for F.E.V.1.0 were computed from the formula:

$$
\frac{\text { F.E.V } \cdot 1.0}{\text { standard error about the regression }}+10
$$

Predicted values were derived from regression equations expressing the relationship of F.E.V. ${ }_{\cdot 1,0}$ to age and height. Sex specific regression equations were developed for three separate age groups; 10-15, 16-19 and 20-74. For men and women aged 16-74, only those who denied having cough, phlegm or shortness of breath contributed to the

*Model 170 Med. Science Electrunics. 
regression equations. The scoring procedure resulted in an overall mean score of 10.0 for persons without respiratory symptoms; values less than this indicate ventilatory lung function below the average for healthy persons of the same sex, age and height [5].

Scores have also been classified as upper, middle or lower tertile according to their rank in the distribution of scores for the appropriate age- and sex-specific segment of the population. In some analyses, correlations of scores have been used; in others, distributions of tertile ranks of these scores have been compared.

Familial aggregation of chronic respiratory disease and resemblance in ventilatory lung function have been sought among parents and children, within sibships and between spouses. Statistical significance has been assessed by chi square tests for association of diseases and by significance of correlations for F.E.V $\cdot_{\cdot 1.0}$ scores.

Table 1. COMposition OF Families eXamined IN TeCumseh 1962-1965

\begin{tabular}{|c|c|c|c|c|c|c|c|c|c|c|}
\hline \multirow{3}{*}{$\begin{array}{l}\text { Number of } \\
\text { sibs examined }\end{array}$} & \multicolumn{10}{|c|}{ Number of parents examined } \\
\hline & \multicolumn{2}{|c|}{ None } & \multicolumn{2}{|c|}{ Father only } & \multicolumn{2}{|c|}{ Mother only } & \multicolumn{2}{|c|}{ Both } & \multicolumn{2}{|c|}{ Total } \\
\hline & No. & $\%$ & No. & $\%$ & No. & $\%$ & No. & $\%$ & No. & $\%$ \\
\hline None & 3346 & 36.3 & 73 & 0.8 & 309 & 3.3 & 394 & 4.3 & 4122 & 44.7 \\
\hline One & 558 & 6.0 & 60 & 0.7 & 246 & 2.7 & 1026 & 11.1 & 1890 & 20.5 \\
\hline Two & 177 & 1.9 & 39 & 0.4 & 216 & 2.3 & 978 & 10.6 & 1410 & 15.3 \\
\hline Three & 48 & 0.5 & 16 & 0.2 & 100 & 1.1 & 752 & 8.2 & 916 & 9.9 \\
\hline Four or more & 43 & 0.5 & 22 & 0.2 & 156 & 1.7 & 667 & 7.2 & 888 & 9.6 \\
\hline Total & 4172 & 45.2 & 210 & 2.3 & 1027 & 11.1 & 3817 & 41.4 & 9226 & 100.0 \\
\hline
\end{tabular}

\section{RESULTS}

The distribution of the 9.226 study subjects according to sibship size and parental examination status is shown in Table 1. Only examined individuals have been counted in determination of sibship size. About two-thirds of the population (64 per cent) had at least one sib or one parent who was examined. Nearly half the population (46 per cent) had both a sib and a parent who participated in the Study. About a third of the population ( 36 per cent) had neither a sib nor a parent in the Study population but 71 per cent of these people were parents of children included in the Study. Thus, 89 per cent of the entire population had one or more first-degree relatives who were also examined. Of the 5054 examined offspring with examined parents, 3817 (76 per cent) had both parents examined; 1027 ( 20 per cent) had only the mother examined and 210 (4 per cent) had only the father. The numbers and proportions of offspring with examined parents decreased with increasing age (Table 2), partly because older persons usually do not live with or even near their parents, and partly because parents of older persons are more likely to have died. Among children less than 16 yr old, only 6 per cent had neither parent examined, whereas 58 per cent of adults aged 16-39, and 91 per cent of adults 40 and over were in this category. Similar explanations hold for the increase with age in the proportion of the population who had no brothers or sisters examined (sibships size one Table 3 ). Thus, 11 per cent of children less than 10,18 per cent of children aged 10-15, 63 per cent of adults aged 16-39 and 83 per cent of those aged 40 or more did not have a sib in the Tecumseh Study population. Many sibships were incomplete, particularly at older ages. Adopted and stepchildren and half-sibs 
have not been counted as first degree relatives and those with biologically incompatible blood types have also been excluded. There were 1947 husband and wife pairs in the examined population; none of these marriages was known to be consanguineous.

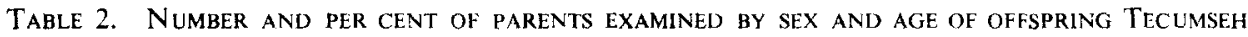
$1962-1965$

\begin{tabular}{|c|c|c|c|c|c|c|c|c|c|c|}
\hline \multirow{3}{*}{$\begin{array}{l}\text { Sex and } \\
\text { age of } \\
\text { offspring }\end{array}$} & \multicolumn{10}{|c|}{ Number of parents examined } \\
\hline & \multicolumn{2}{|c|}{ None } & \multicolumn{2}{|c|}{ Father only } & \multicolumn{2}{|c|}{ Mother only } & \multicolumn{2}{|c|}{ Both } & \multicolumn{2}{|c|}{ Total } \\
\hline & No. & $\%$ & No. & $\%$ & No. & $\%$ & No. & $\%$ & No. & $\%$ \\
\hline \multicolumn{11}{|l|}{ Male } \\
\hline $0-9$ & 69 & 5.7 & 31 & 2.6 & 165 & 13.6 & 944 & 78.1 & 1209 & 100 \\
\hline $10-15$ & 43 & 6.3 & 27 & 4.0 & 107 & 15.7 & 505 & 74.0 & 682 & 100 \\
\hline $16-39$ & 757 & 53.4 & 50 & 3.5 & 162 & 11.4 & 448 & 31.6 & 1417 & 100 \\
\hline $40+$ & 1066 & 91.0 & 10 & 0.9 & 63 & 5.4 & 32 & 2.7 & 1171 & 100 \\
\hline Total & 1935 & 43.2 & 118 & 2.6 & 497 & 11.1 & 1929 & 43.1 & 4479 & 100 \\
\hline \multicolumn{11}{|l|}{ Female } \\
\hline $0-9$ & 54 & 4.4 & 29 & 2.4 & 171 & 13.9 & 975 & 79.3 & 1229 & 100 \\
\hline $10-15$ & 37 & 5.8 & 13 & 2.0 & 112 & 17.5 & 479 & 74.7 & 641 & 100 \\
\hline $16-39$ & 979 & 61.2 & 40 & 2.5 & 183 & 11.4 & 398 & 24.8 & 1600 & 100 \\
\hline $40+$ & 1167 & 91.4 & 10 & 0.8 & 64 & 5,0 & 36 & 2.8 & 1277 & 100 \\
\hline Total & 2237 & 47.1 & 92 & 1.9 & 530 & 11.2 & 1888 & 39.8 & 4747 & 100 \\
\hline \multirow{2}{*}{\multicolumn{11}{|c|}{ Both sexes }} \\
\hline & 4172 & 45.2 & 210 & 2.3 & 1027 & 11.1 & 3817 & 41.4 & 9226 & 100 \\
\hline
\end{tabular}

TABle 3. NUMBIR OF SIBSHIPS by SIBSHIP SIZE (EXAMINED MEMBERS ONLY) AND AGE OF YOUNGEST SIB

\begin{tabular}{|c|c|c|c|c|c|c|c|c|c|c|c|c|c|}
\hline \multirow{3}{*}{$\begin{array}{l}\text { Age of } \\
\text { youngest } \\
\text { sib }\end{array}$} & \multicolumn{12}{|c|}{ Sibship size } & \multirow{3}{*}{$\begin{array}{c}\text { No. of } \\
\text { individuals }\end{array}$} \\
\hline & & & \multicolumn{2}{|c|}{3} & \multicolumn{2}{|l|}{4} & \multicolumn{2}{|c|}{$5+$} & \multicolumn{2}{|c|}{ Total } & \\
\hline & No. & $\%$ & & $\because$ & No, & $\%$ & No. & $\%$ & No. & $\%$ & No. & $\%$ & \\
\hline $0-9$ & 344 & 27.5 & 344 & 27.5 & 261 & 20.8 & 175 & 14.0 & 128 & 10.2 & 1252 & 100 & 3252 \\
\hline $10-15$ & 174 & 37.1 & 162 & 34.5 & 87 & 18.6 & 32 & 6.8 & 14 & 3.0 & 469 & 100 & 966 \\
\hline $16-39$ & 1690 & 80.2 & 300 & 14.2 & 85 & 4.0 & 20 & 0.9 & 13 & 0.6 & 2108 & 100 & 2697 \\
\hline 40 & 1914 & 91.5 & 139 & 6.6 & 37 & 1.8 & 2 & 0.1 & 0 & 0.0 & 2092 & 100 & 2311 \\
\hline Total & 4122 & 69.6 & 945 & 16.0 & 470 & 7.9 & 229 & 3.9 & 155 & 2.6 & 5921 & 100 & 9226 \\
\hline
\end{tabular}

Chronic respiratory disease in parents and children

The prevalence of chronic bronchitis, asthma and allergic rhinitis in male and female offspring of different ages has been related to the presence or absence of parental disease (Table 4). Chronic bronchitis was diagnosed more frequently when one or both parents were affected than when neither was. The differences were greatest and statistically significant for male and female offspring aged 16-39. The prevalences of asthma and allergic rhinitis were also greater when one or both parents had the same disease and these differences were significant for sons and daughters aged less than 16 and 16-39 yr. In most age and sex groups, parent-child similarity in disease experience was greater for allergic rhinitis than for asthma. There were very few families in which both parents had the same disease but there was a tendency for the prevalence of disease to be even higher in these offspring than in the offspring of one affected parent (not shown). Small numbers also make it difficult to determine whether the sex of the 
affected parent influenced the prevalence of disease in the offspring. When one parent had chronic bronchitis, it was more often the father than the mother, and the prevalence of chronic bronchitis was higher in sons than daughters. This preponderance of affected males occurs in the general population of Tecumseh and elsewhere $[5,6]$. Asthma was also more frequent among sons than daughters below the age of 40 , but the affected parent was as often the mother as the father. By contrast, allergic rhinitis occurred a little more often in daughters than sons after age 15, and the affected parent was more often the mother than the father. However, there was no evidence to suggest that the relative increase in occurrence of disease in offspring of affected parents was influenced by the sex of the affected parent for either chronic bronchitis or asthma. Allergic rhinitis was diagnosed more often in offspring of affected mothers than fathers, when the offspring were aged less than 40 .

Table 4. Chronic bronchitis, asthma AND ALlergic RHINITIS IN Parents and CHILDREN PREVALENCE (PER CENT) IN OFFSPRING BY SEX AND AGE OF OFFSPRING AND DIAGNOSIS OF PARENTS

\begin{tabular}{|c|c|c|c|c|c|c|c|}
\hline \multirow[b]{2}{*}{ Condition } & \multirow[b]{2}{*}{$\begin{array}{l}\text { Parents } \\
\text { diagnosis }\end{array}$} & \multicolumn{6}{|c|}{ Sex and age of offspring } \\
\hline & & $\begin{aligned} & <16 \\
N & =1779\end{aligned}$ & $\begin{array}{c}\text { Male } \\
16-39 \\
N=660\end{array}$ & $\begin{array}{c}40+ \\
N=105\end{array}$ & $\begin{aligned} & <16 \\
N & =1779\end{aligned}$ & $\begin{array}{c}\text { Female } \\
16-39 \\
N=621\end{array}$ & $\stackrel{40+}{N=110}$ \\
\hline Chronic bronchitis & $\begin{array}{l}\text { both negative } \\
\text { one or both positive }\end{array}$ & & $\begin{array}{c}6.3 \\
17.3 * *\end{array}$ & $\begin{array}{l}13.8 \\
16.7\end{array}$ & & $\begin{array}{l}2.0 \\
6.6^{*}\end{array}$ & $\begin{array}{l}6.9 \\
8.3\end{array}$ \\
\hline Asthma & $\begin{array}{l}\text { both negative } \\
\text { one or both positive }\end{array}$ & $\begin{array}{c}7.4 \\
18.3^{* *}\end{array}$ & $\begin{array}{r}8.3 \\
12.2\end{array}$ & $\begin{array}{c}3.2 \\
(0.0)\end{array}$ & $\begin{array}{l}4.1 \\
11.7^{* *}\end{array}$ & $\begin{array}{l}4.9 \\
13.0^{* *}\end{array}$ & $\begin{array}{l}15.4 \\
10.0\end{array}$ \\
\hline Allergic rhinitis & $\begin{array}{l}\text { both negativc } \\
\text { one or both positive }\end{array}$ & $\begin{array}{l}3.4 \\
13.5^{* *}\end{array}$ & $\begin{array}{l}12.4 \\
32.1 * *\end{array}$ & $\begin{array}{l}17.4 \\
30.8\end{array}$ & $\begin{array}{l}2.9 \\
10.9^{* *}\end{array}$ & $\begin{array}{l}14.9 \\
25.2^{* *}\end{array}$ & $\begin{array}{l}29.6 \\
29.4\end{array}$ \\
\hline
\end{tabular}

() denominator $<10$

${ }^{* *} p<0.01$

$* p<0.05$

\section{Chronic respiratory disease in sibs}

The occurrence of disease in sibships is described by sibship size in Table 5. The observed frequencies are shown and must be compared with the expected frequencies which are based on the age-sex specific prevalence rates for the Tecumseh population. Aggregation of disease is indicated by a greater than expected number of sibships with more than one sib affected. Such a pattern was seen for all three diseases in sibships consisting of two and three examined members, and in larger sibships for asthma. However, the number of sibships with two or more affected members was small. There were only 17 sibships with at least two chronic bronchitics, 44 with at least two asthmatics and 53 with at least two persons with allergic rhinitis. When comparisons were sex-specific and within age groups of less than $16 \mathrm{yr}, 16-39 \mathrm{yr}$ and 40 and over according to the age of the younger sib, the numbers of affected sibships and the differences between observed and expected values were small (data not shown). They suggest that sibling resemblance for chronic bronchitis occurs among males agcd 16-39, among females aged 40 and over and, to a lesser extent, among sibs of opposite sex in both age groups. Sibling aggregation of asthma occurred among males sibs aged less than 16, among female sibs less than 16 and 16-39 and among sibs of opposite sex aged 16-39 and 40 and over. Allergic rhinitis was observed more often than expected in both sibs no matter whether both were male or female or one was of each sex. 


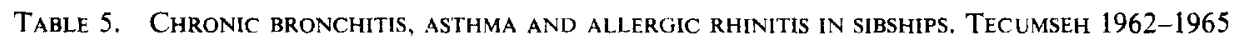

\begin{tabular}{|c|c|c|c|c|c|c|c|}
\hline \multirow{3}{*}{$\begin{array}{l}\text { No. } \\
\text { examined } \\
\text { sibs. }\end{array}$} & \multirow{3}{*}{$\begin{array}{c}\text { No. } \\
\text { diag. } \\
\text { per } \\
\text { sibship }\end{array}$} & \multicolumn{6}{|c|}{ Diagnosis } \\
\hline & & \multicolumn{2}{|c|}{ Chronic bronchitis* } & \multicolumn{2}{|c|}{ Asthma } & \multicolumn{2}{|c|}{ Allergic rhinitis } \\
\hline & & No. obs. & No. exp. & No. obs. & No. exp. & No. obs. & No. exp. \\
\hline \multirow{3}{*}{2} & 0 & 350 & 355.9 & 835 & 825.1 & 779 & 775.3 \\
\hline & I & 79 & 78.4 & 102 & 115.6 & 144 & 158.9 \\
\hline & 2 & 10 & 4.8 & 8 & 4.2 & 22 & 10.7 \\
\hline \multirow{4}{*}{3} & 0 & 88 & 90.0 & 381 & 383.0 & 362 & 365.6 \\
\hline & 1 & 29 & 28.4 & 70 & 81.0 & 85 & 93.0 \\
\hline & 2 & 4 & 3.5 & 16 & 5.9 & 18 & 10.9 \\
\hline & 3 & 1 & 0.2 & 3 & 0.1 & 5 & 0.5 \\
\hline \multirow{5}{*}{4} & 0 & 12 & 14.6 & 178 & 174.1 & 177 & 172.5 \\
\hline & 1 & 9 & 6.3 & 39 & 49.3 & 47 & 48.9 \\
\hline & 2 & 1 & 1.1 & 11 & 5.6 & 5 & 7.4 \\
\hline & 3 & 0 & 0.1 & 1 & 0.3 & 0 & 0.5 \\
\hline & 4 & 0 & 0.0 & () & 0.0 & 0 & 0.0 \\
\hline \multirow{6}{*}{5} & () & 5 & 4.9 & 66 & 66.2 & 68 & 65.3 \\
\hline & 1 & 2 & 2.5 & 22 & 24.0 & 23 & 23.8 \\
\hline & 2 & 1 & 0.5 & 3 & 3.5 & 2 & 4.4 \\
\hline & 3 & 0 & 0.1 & 2 & 0.3 & 1 & 0.5 \\
\hline & 4 & 0 & 0.0 & 0 & 0.0 & 0 & 0.0 \\
\hline & 5 & 0 & 0.0 & 0 & 0.0 & 0 & 0.0 \\
\hline
\end{tabular}

*Sibships with one or more persons under age 16 excluded.

Expected frequencies are based on age-sex specific prevalence rates for the Tecumseh population.

\section{Chronic respiratory disease in spouses}

The third group examined for concurrence of disease experience was spouses (Table 6). The prevalence of chronic bronchitis was greater among wives of men with chronic bronchitis whereas asthma and allergic rhinitis occurred with equal or greater frequency when the husband was not affected. However, the differences for chronic bronchitis were not statistically significant.

Table 6. Chronic bronchitis, asthma and allergic RHINitis in Spouses PRFVAI FNCF. (PFR CFNT) IN WIVFS RY AGiF OF WIFF ANI) DIAGNOSIS OF HIISRAND

\begin{tabular}{llccc}
\hline \multirow{2}{*}{$\begin{array}{l}\text { Cusbands } \\
\text { Condition }\end{array}$} & $\begin{array}{c}\text { Age of wife } \\
\text { diagnosis }\end{array}$ & $\begin{array}{c}16-39 \\
N=1089\end{array}$ & $\begin{array}{c}40+ \\
N=858\end{array}$ & $\begin{array}{c}\text { Total } \\
N=1947\end{array}$ \\
\cline { 5 - 5 } Chronic bronchitis & negative $N=1620$ & 4.7 & 4.8 & 4.8 \\
Asthma & positive $N=327$ & 7.3 & 6.7 & 7.0 \\
& negative $N=1830$ & 5.8 & 7.1 & 6.3 \\
Allergic rhinitis & positive $N=117$ & 6.0 & 6.0 & 6.0 \\
& negative $N=1699$ & 14.6 & 14.5 & 14.6 \\
& positive $N=248$ & 12.9 & 8.3 & 10.9 \\
\hline
\end{tabular}

\section{Ventilatory capacity}

Ventilatory capacity is a continuous variable like height, blood pressure or intelligence. Its distribution in first-degree relatives has not previously been studied in 
a general population, whereas a good deal of attention has been given to assessing the contributions of genetic and environmental influences to the other characteristics. Although there are some obvious differences in the determinants of height and ventilatory capacity, the data on familial resemblance in height for the Tecumseh population are presented as standards with which the findings on lung function may be compared.

\section{Ventilatory capacity in parents and children}

Correlations of children's F.E.V $\cdot_{1.0}$ scores with parents F.E.V $\cdot_{1.0}$ scores are shown in Table 7. Statistically significant correlations were found between parents and their children when the latter were less than $40 \mathrm{yr}$ old. In general they were greater for children under 16 than for children aged 16-39. They were greater for fathers and sons and for mothers and daughters than for fathers and daughters or mothers and sons. Correlations with the mid-parent value (average of fathers and mothers values) were sometimes intermediate between the values for the two parents, but sometimes they were higher. Regressions of F.E.V $\cdot_{1.0}$ scores of children on F.E.V $\cdot_{1.0}$ scores of parents are shown by age and sex of child in Fig. 1 . The percentage of offspring whose F.E.V.1.0 score was in the lowest, middle or highest tertile was calculated according to parental tertile ranks (Fig. 2). The percentage of children with low F.E.V ${ }_{1.0}$ scores was greatest (49 per cent) when both parents had low values and least ( 21 per cent) when both parents had high values. Conversely, only 19 per cent of of fspring had values in the highest tertile if both parents had lowest tertile values, whereas 50 per cent of offspring had values in the highest tertile if both parents had highest tertile values.

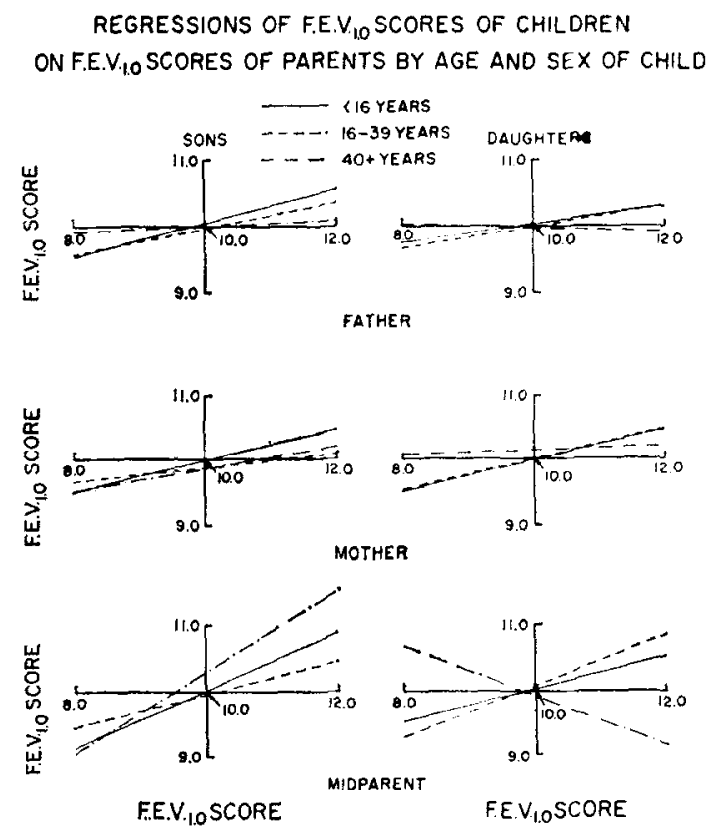

FIG. 1. Regressions of F.E.V.1.0 scores of children on F.E.V.I.0 scores of parents by age and sex of child. 
Table 7. Correlations of Childrens Value with Parents Value for F.E.V.1.0 SCORE AND FOR HEIGHT BY SEX AND AGE OF CHILD

\begin{tabular}{|c|c|c|c|c|c|c|c|c|c|}
\hline \multirow[b]{2}{*}{ Relationship } & \multicolumn{9}{|c|}{ Age of child } \\
\hline & $N \dot{\varphi}$ & $\begin{array}{l}10-15 \\
\text { F.E. }{ }^{\prime} \cdot 1.0\end{array}$ & Height & $N \dagger$ & $\begin{array}{l}16-39 \\
\text { F.E.V. } 1,0\end{array}$ & $\begin{array}{c}r \\
\text { Height }\end{array}$ & $\mathrm{NH}$ & $\begin{array}{c}40+ \\
r \\
\text { F.E.V. } 1.0\end{array}$ & $\begin{array}{c}r \\
\text { Heiglit }\end{array}$ \\
\hline Father, son & 500 & $0.27^{* *}$ & $0.14^{* *}$ & 451 & $0.21 * *$ & $0.53 * *$ & 32 & 0.05 & $0.47 * *$ \\
\hline Father, daughter & 452 & $0.16^{* *}$ & $0.15 *$ & 390 & $0.18 * *$ & $0.37 * *$ & 41 & -0.03 & 0.21 \\
\hline Mother, son & 560 & $0.23^{* *}$ & $0.19^{* *}$ & 536 & $0.10^{*}$ & $0.39 * *$ & 71 & 0.14 & $0.52 * *$ \\
\hline Mother, daughter & 533 & $0.24^{* *}$ & $0.29 * *$ & 505 & $0.22 * *$ & $0.52 * *$ & 76 & 0.03 & $0.46^{* *}$ \\
\hline Midparent, son & 455 & $0.33^{* *}$ & $0.19^{* *}$ & 379 & $0.19 * *$ & $0.57 * *$ & 24 & 0.28 & $0.63 * *$ \\
\hline $\begin{array}{l}\text { Midparent, } \\
\text { daughter }\end{array}$ & 423 & $0.21^{* *}$ & $0.29 * *$ & 345 & $0.31 * *$ & $0.59 * *$ & 28 & -0.20 & 0.30 \\
\hline
\end{tabular}

$\uparrow N$ is the number of parent-offspring pairs with F.E.V.1.0 scores.

$\begin{aligned} * * p & <0.01 \\ * p & <0.05\end{aligned}$

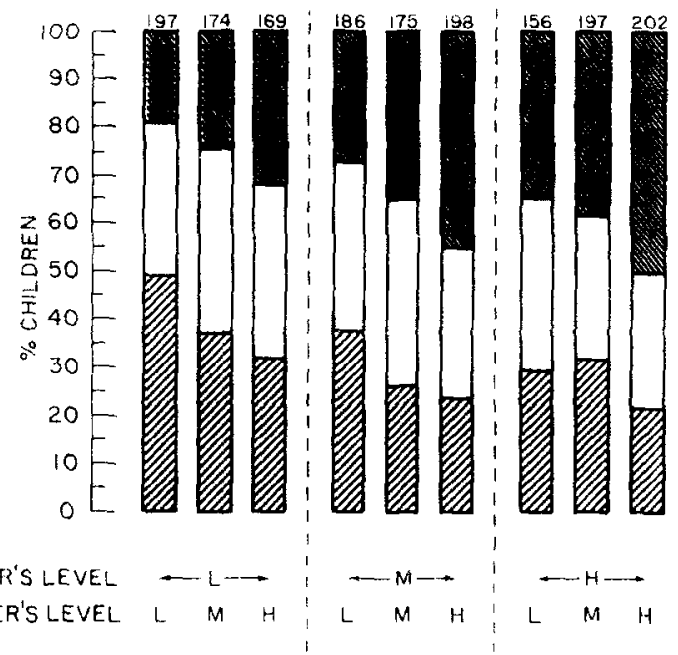

$\begin{array}{ll}\text { L LOWEST TERTILE } & \text { CHILOREN IN UPPER TERTILE } \\ M \text { MIDDLE TERTILE } & \text { CHILDREN IN MOOLE TERTILE } \\ \text { H HIIGHEST TERTILE } & \text { EZO CHIIDREN IN LOWER TERTILE }\end{array}$

FIG. 2. Tertile ranks of F.E.V.1.0 scores of children by tertile ranks of F.E.V 1.0 scores of parents.

Ventilatory' capacity in sibs

Intraclass correlation coefficients of F.E.V. ${ }_{1.0}$ scores were calculated for two-person sibships classified by sex and age of the younger sib (Table 8). The intraclass correlation is equivalent to a product-moment correlation with the members of each pair entered into the calculation twice, once in each order. This eliminates the need to designate one member of the sibship pair as an index. The coefficients were statistically significant in every case but one and they were higher for sibs of the same sex than for sibs of opposite sex. They were higher for males than females after age 16. 
Tertile ranks of F.E.V $\cdot_{1,0}$ scores of sibs were compared and there was a slight excess of sib pairs where both had low values and a slight deficiency of sib pairs where disagreement between the two was maximal i.e. one had a low F.E.V.1.0 score and the other a high one.

TABle 8. INTRAClass CORRELATION COEFficients $\left(R_{I}\right)$ of F.E.V.1.0 SCORES AND OF height for SIBSHIPS OF SIZE TWO BY SEX AND AGE OF YOUNGER SIB

\begin{tabular}{|c|c|c|c|c|c|c|c|c|c|}
\hline \multirow[b]{2}{*}{ Sex of sibs } & \multicolumn{9}{|c|}{ Age of younger sib } \\
\hline & $N \dagger$ & $\begin{array}{c}10-15 \\
R_{\mathrm{I}} \\
\text { F.E.V.1.0 }\end{array}$ & $\underset{\text { Height }}{R_{\mathrm{I}}}$ & $N+$ & $\begin{array}{c}16-39 \\
R_{\mathbf{I}} \\
\text { F.E.V.1.0 }\end{array}$ & $\begin{array}{c}R_{\mathbf{I}} \\
\text { Height }\end{array}$ & $N \dagger$ & $\begin{array}{c}40+ \\
R_{I} \\
\text { F.E.V.1.0 }\end{array}$ & $\begin{array}{c}R_{\mathrm{I}} \\
\text { Height }\end{array}$ \\
\hline Both male & 43 & $0.46 * *$ & $0.36^{* *}$ & 65 & $0.40^{* *}$ & $0.51 * *$ & 32 & $0.50^{* *}$ & $0.35^{*}$ \\
\hline Both female & 26 & $0.66^{* *}$ & 0.16 & 61 & $0.23^{*}$ & $0.56^{*}$ & 34 & $0.32 *$ & $0.30^{*}$ \\
\hline $\begin{array}{l}\text { One male and } \\
\text { one female }\end{array}$ & 83 & $0.23^{*}$ & 0.08 & 140 & $0.17^{*}$ & -0.40 & 56 & 0.06 & -0.36 \\
\hline
\end{tabular}

$\dagger N$ is the number of sibships with F.E.V.1.0 scores.

$* * p<0.01$

${ }^{*} p<0.05$

\section{Ventilatory capacity in spouses}

Spouse pairs were classified by age of wife. Correlations of F.E.V $\cdot_{1,0}$ scores of spouses were appreciably smaller than the values for parents and children or sibs, being 0.12 for pairs with wives aged $16-39$ and 0.16 for older pairs. They were statistically significant $(p<0.01)$ for both age groups (Table 9 ).

There was a slight excess of spouse pairs with similar tertile ranks of F.E.V $\cdot_{1.0}$ scores and a slight deficiency of spouse pairs with the most discrepant values.

TAble 9. Correlations between F.E.V.1.0 SCORES AND HEIGHTS OF SPOUSES BY AGE OF WIFE

\begin{tabular}{lccccc}
\hline & \multicolumn{4}{c}{ Age of wife } \\
\cline { 2 - 5 } & \multicolumn{2}{c}{$16-\overline{39}$} & \multicolumn{2}{c}{$40+$} \\
& $N \dagger$ & $r$ & $N+$ & $r$ \\
\hline F.E.V.1.0 Scure & 997 & $0.18^{* *}$ & 773 & $0.16^{* *}$ \\
Height & & $0.14^{* *}$ & & $0.19^{* *}$ \\
\hline
\end{tabular}

$+N$ is the number of spouse pairs

$* * p<0.01$

$* p<0.05$

\section{DISCUSSION}

Studies of chronic respiratory disease and ventilatory lung function in Tecumseh, and elsewhere, have shown that related personal and environmental factors include cigarette smoking, acute respiratory infections, allergic conditions, air pollution, occupation and other socioeconomic characteristics [5, 8, 9]. Familial factors include all of these influences as well as inherited and other characteristics. However, identification of specific etiologic components which together constitute the familial influence, is not easy. The size of the Tecumseh population and the design of the study impose 
limitations. Families living in a geographically defined community are more likely to be complete at young ages whereas chronic bronchitis and impaired lung function are more prevalent at older ages. Thus, in a community of about 10,000 people, there are relatively few families in which two or more persons suffer from the same chronic respiratory disease. Lack of diagnostic precision is another obstable to identifying specific etiologies for heterogeneous conditions like chronic bronchitis and asthma. Interpretation of the data is further complicated by the population structure for the observations are not independent since one person may be involved more than once in any analysis. For example, a father with three examined children would be involved three times in the parent-offspring correlations. He might also be involved as a son in the same analysis if his father had been examined. Nevertheless, it may be possible to take recognized biases in the data into account, when the findings are interpreted.

The importance of environmental determinants of respiratory disability has been clearly recognized for some time $[7,10]$; the possible role of genetic and other host factors in increasing susceptibility to environmental hazards has also received a good deal of attention in recent years [11, 12]. In the 1950's, English workers reported that more chronic bronchitics than nonbronchitics said they had first-degree relatives with chronic bronchitis [13]. Familial, possibly hereditary factors have been implicated in the development of asthma and allergic rhinitis. Some authors have postulated dominant inheritance with or without reduced penetrance but some think multifactorial inheritance is just as compatible with the data [13-16]. Genetic factors have been implicated in the development of a small proportion of cases of pulmonary emphysema [17] but it is not definitely established whether interaction between milder genetic defects and exposure to environmental hazards accounts for a significant part of the respiratory disease problem. From twin studies designed to estimate the relative significance of smoking and heredity it was concluded that both factors influenced the development of chronic obstructive pulmonary disease [18].

The present report shows that there is familial clustering of chronic bronchitis, asthma and allergic rhinitis in Tecumseh and that members of families resemble one another in level of ventilatory lung function. Marked familial resemblance in smoking habits has also been found in this population [19]. An attempt will be made in the discussion to assess the contributions of inheritance and environment-especially smoking habits, to the present findings.

First-degrec relatives have half their autosomal gencs in common, regardless of sex and current age. Whereas environmental exposures, including smoking habits, are more likely to be similar if first-degree relatives are of the same sex and close to one another in age. In the absence of consanguineous and assortative mating, one could attribute spouse resemblances to similar environmental exposures; however, although there is no known consanguinity among Tecumseh spouses, assortative mating did occur, at least for height. Some similarities and some differences in familial patterns were found for the three diseases considered. The excessive prevalence of disease among offspring of affected parents was least, or even absent, for all three discascs when the offspring were aged 40 or more. This may mean that heredity is relatively less important at older ages, or that the oldest offspring and parents shared fewer hazardous environmental exposures, or that offspring aged 40 and over with surviving parents, are an unrepresentative, possibly healthier, segment of the original population to which they belonged. The data on asthma and allergic rhinitis support the suggestion 
that genetic factors are more important early in life since the excessive prevalence of disease in offspring of affected parents was greatest when the offspring were aged less than 16 , and it is unlikely that similarity in relevant environmental exposures would increase with decreasing age of parents and children. The trend towards a higher prevalence in offspring when both parents were affected than when only one was, is consistent with either a genetic or an environmental interpretation; a similar situation occurred for cigarette smoking [19]. Unfortunately, the numbers of affected sibs were small and it is difficult to draw any conclusions except that aggregation of all three diseases occurred and affected both sexes. In general, sibling resemblance tended to be greater at younger ages. Spouse similarity in occurrence of disease was present only for chronic bronchitis.

Familial resemblance in age- and height-adjusted F.E.V. $\cdot_{1,0}$ scores was found among each of the three sets of relatives but it was less among spouses than among parents and children or sibs. Among the first-degree relatives correlations were generally higher at younger ages and among persons of the same sex. Correlations for height showed a similar pattern among sibs but they were least between parents and children aged 10-15-for obvious reasons.

Familial aggregation of smoking habits was found in Tecumseh between parents and children, among sibs and between husbands and wives. Resemblance in smoking habits also tended to be greater at younger ages and among persons of the same sex and there was, of course, a preponderance of male smokers. Thus, the current findings on chronic bronchitis are consistent with expectations based on knowledge of the distribution of smoking habits in families. But this explanation does not account for all the familial resemblance in ventilatory capacity since resemblance in level of F.E.V $\cdot_{1.0}$ score was not confined to the lower end of the range but was present also in the middle and upper levels. Resemblance was also greatest when children or sibs were aged less than $16 \mathrm{yr}$, at which ages practically no children in Tecumseh smoked cigarettes. The greater resemblance in lung function between first-degree relatives of the same sex is also present in the youngest age group and cannot, therefore, be explained entirely on the basis of greater similarity in smoking habits between members of the same sex. Unfortunately, lack of numbers precludes the obvious approach of examining relationships among family members who have similar smoking habits. No association has been found between asthma or allergic rhinitis and smoking habits in previous analyses of the Tecumseh data [8] nor is any such association suggested by the familial clustering reported here. Again small numbers make it difficult to identify the mechanism of inheritance of the postulated genetic causes of these conditions.

Associations between chronic respiratory diseases, ventilatory capacity, smoking habits and 13 genetic markers will be sought in further analyses of the data. Analyses will also test the hypothesis that part of the familial aggregation of chronic bronchitis, asthma, and allergic rhinitis, and some of the resemblance in ventilatory lung function can be explained by similarity among first-degree relatives in marker genes considered specifically and as 'labels' on small pieces of chromosomes.

The results presented show that patterns of clustering and resemblance vary with disease as well as with age and sex. They implicate both environmental and genetic factors as determinants of chronic bronchitis, asthma, allergic rhinitis and level of ventilatory capacity. 


\section{SUMMARY}

One of the main hypotheses of the Tecumseh Study is that no matter whether genetic, constitutional or environmental factors are involved, new cases of disease will occur among family members of affected persons. During the second cycle of examinations, 82 per cent of the population were examined. Eighty-nine per cent of these 9226 persons had one or most first-degree relatives who was also a member of the study population. We have found that the prevalences of chronic bronchitis, asthma and allergic rhinitis were higher in the offspring when one or both parents were affected than when neither was. Clustering of these conditions also occurred in affected sibships but there was evidence of disease aggregation among spouses only for chronic bronchitis. There were statistically significant correlations of parents' lung function variables with those of their children and these were greater at younger than older ages and when parent and child were of the same sex. Intraclass correlation coefficients of F.E.V. ${ }_{1,0}$ scores for two-person sibships were statistically significant and varied with sex and age of the sibs. Statistically significant correlations were also found between F.E.V.1.0 scores of spouses but these were appreciably smaller than those between first-degree relatives. The scores of the variables are age- and height-adjusted and therefore, the resemblances in lung function are not merely a reflection of resemblances in height.

The patterns of clustering and resemblance vary with disease as well as with age and sex. They implicate both environmental and genetic factors as determinants of chronic bronchitis, asthma, allergic rhinitis and level of ventilatory capacity.

\section{REFERENCES}

1. Epstein FH, Napier JA, Block WD, Hayner NS, Higgins MW, Johnson BC, Keller JB, Metzner HL, Montoye HJ, Ostrander LD, Jr, UIlman BM (The senior research colleagues of the late Dr. Thomas Francis, Jr): The Tecumseh Study: design, progress and perspectives. Arch Env Hith $21: 402-407,1970$

2. Napier JA, Johnson BC, Epstein FH: The Tecumseh Community Health Study. In: Casebook of Community Studies. Kessler II, Levin ML (Eds). Chapter 2, 25 46. Baltimore: Johns Hopkins Press, 1970

3. Epstein FH, Francis T, Jr, Hayner NS, Johnson BC, Kjelsberg MO, Napier JA, Ostrander LD, $\mathrm{Jr}$, Payne MW, Dodge HJ: Prevalence of chronic diseases and distribution of selected physiologic variables in a total community-Tecumseh, Michigan. Am J Epid 81: 307-322, 1965

4. Broder I, Higgins MW, Mathews KP, Keller JB: Epidemiology of asthma and allergic rhinitis in a total community, Tecumseh, Michigan. J. Allergy Clin Immunol 53, (3), 127-138, 1974

5. Higgins MW, Keller JB: Seven measures of ventilatory lung function. Population values and a comparison of their ability to discriminate between persons with and without chronic respiratory symptoms and disease. Tecumseh, Michigan. Am Rev Resp Dis 108: 258-272, 1973

6. Payne MW, Kjelsberg MO: Respiratory symptoms, lung function and smoking habits in an adult population. Am J Publ Hith 54: 261-277, 1964

7. U.S. Public Health Service: The health consequences of smoking. A report of the surgeon general. 1971, 1972 and 1973. D.H.E.W. Publication Numbers (HSM) 71-7513, 72-7516, 73-8704

8. Higgins MW, Keller JB: Cigarette smoking, respiratory infection and allergy in relation to chronic bronchitis in Tecumseh. Unpublished

9. Higgins MW, Keller JB: Occupational and socioeconomic factors related to chronic respiratory disease and ventilatory capacity. In preparation

10. U.S. Public Health Service: Smoking and health. Report of the advisory committee to the surgeon general of the public health service. Washington: Public Health Service Publication No. 1103,1964

11. Kueppers F, Fallat R, Larson RK: Obstructive lung disease and alpha ${ }_{1}$ antitrypsin deficiency gene heterozygosity. Science 165: 899-901, 1969

12. Larson RK, Barman ML, Kueppers F, Fudenberg HH: Genetic and environmental determinants of chronic obstructive pulmonary disease. Ann Int Med 72: 627, 1970 
13. Ogilvie AG, Newell DJ: Chronic Bronchitis In Newcastle-upon-Tyne. Edinburgh and London: E.S. Livingstone Ltd, 1957

14. Schwartz M: Heridity in bronchial asthma. Acta Allerg 5: Supplement 2, 1952

15. Lubs MLE: Empiric risks for genetic counseling in families with allergy. J Pediat 80: 26-31, 1972

16. Leigh D, Marley E: Bronchial asthma. A genetic, population and psychiatric study. Oxford: Pergamon, 1967

17. Larson RK, Barman ML: The familial occurrence of chronic obstructive pulmonary disease. Ann Int Med 63: 1001-1008, 1965

18. Cederlof $R$, Friberg L, Hrubec $Z$ : Cardiovascular and respiratory symptoms in relation to tobacco smoking. Arch. Env Hith 18: 934-940, 1969

19. Higgins MW, Kjelsberg MO, Metzner HL: Characteristics of smokers and nonsmokers in Tecumseh, Michigan-I. The distribution of smoking hahits in persons and families and their relationship to social characteristics. Am J Epid 86: 45-59, 1967 